\title{
CIDADANIA, CONFIANÇA E INSTITUIÇÕES DEMOCRÁTICAS
}

\author{
José Álvaro Moisés
}

Até recentemente, não era evidente que existissem questões relevantes, tanto de ordem teórica como prática, envolvidas nas relações entre cidadania e confiança em instituições democráticas. A teoria liberal clássica nasceu da desconfiança diante das estruturas tradicionais de poder e a liberdade dos modernos comparada a dos antigos, como Benjamin Constant mostrou em sua célebre conferência de 1819, limitou a soberania dos cidadãos ao instituir o sistema de representação baseado na idéia de que quem escolhe um representante delega o seu poder de decidir.

Foram as extraordinárias transformações políticas das três últimas décadas do século XX, que culminaram com a democratização de vários países da Europa, da América Latina, da Ásia e da África, que provocaram a retomada das abordagens que associam a democracia com a expansão dos direitos dos cidadãos, retomando, mas, ao mesmo tempo, indo além do que T. H. Marshall (1965) e R. Bendix (1977) haviam proposto sobre o tema em meados do século passado. De fato, embora o vínculo entre democracia e os direitos dos cidadãos seja parte da tradição das ciências sociais, a novidade das abordagens atuais, depois de décadas de desu- 
so do conceito de cidadania, está na importância atribuída à confiança dos cidadãos para o funcionamento das instituições democráticas. O que está em questão agora não é apenas a adesão ou obediência cega às instituições públicas, mas a confiança derivada de sua justificação ética e normativa, assim como de seu desempenho.

No Brasil, vários autores trataram das relações entre os efeitos das transformações decorrentes do fim do regime autoritário e a consolidação dos direitos de cidadania, e alguns reconheceram a centralidade da questão para o processo de democratização, mas raramente o problema foi posto em termos das relações entre confiança e instituições públicas. O historiador José Murilo de Carvalho é uma exceção. No livro Cidadania no Brasil - O longo caminho e em outros textos recentes, ele argumentou que o complexo processo de reconstrução das instituições democráticas no país converteu o tema dos direitos de cidadania no foco das expectativas geradas pela reforma das instituições que, em 1988, concluíram com a promulgação da Constituição Cidadã. Mas não deixou de chamar a atenção para o fato de que a reconquista da liberdade e a ampliação de direitos sociais e da participação política não impediram que, o fenômeno de desencanto político e de déficit de confiança dos cidadãos nas instituições democráticas, emergisse associado com as dificuldades dos governos democráticos, para solucionar os problemas sociais e econômicos do país

Outros autores como Elisa Reis (1998), embora partindo de premissas teóricas diferentes, perguntaram, recentemente, por que fomos levados a deslocar gradualmente a discussão da democratização para o terreno da consolidação da cidadania. Suas respostas sugerem que o renascimento do conceito está associado ao fato da cidadania constituir-se em uma espécie de princípio de articulação das demandas por emancipação e por inclusão social que emergem no contexto do conflito de interesses divergentes 
que caracteriza as sociedades complexas, desiguais e diferenciadas. Suas abordagens retomam a análise de Marshall sobre a expansão tridimensional da cidadania, relativa a direitos civis, políticos e sociais, e incorporam a importância da formação das identidades dos atores e de seu impacto sobre as relações de raça, etnia, gênero, etc. para o processo de consolidação da cidadania; alguns se referem também ao papel da participação política para a educação do cidadão ativo, chamando a atenção para a inovação representada por mecanismos semi-diretos da democracia como o referendo, o plebiscito e a iniciativa popular de lei. Nesses casos, superando a perspectiva evolucionista e seqüencial das análises de Marshall, há uma evidente ampliação do conceito de cidadania, mas a questão de saber se, por que e como os cidadãos confiam nas instituições democráticas não está suficientemente desenvolvida, indicando a necessidade de novos estudos e pesquisas sobre o tema.

Em âmbito mais amplo, o registro de mudança da atitude dos cidadãos diante das instituições públicas e, em especial, das instituições democráticas, originando ou aprofundando o fenômeno de desconfiança política em várias partes do mundo, foi documentada por extensa literatura desde os anos 80. Estudos comparativos editados recentemente por Dieter Klingemann (1998), Pippa Norris (1999), Margaret Levi (1998), Joseph Nye (1997) e Mark Warren (1999) apontaram para a complexidade e, principalmente, a grande variação do fenômeno. Nas democracias consolidadas em meados do século XX, como Itália, Japão e, em menor grau, Alemanha, o cinismo e o desconforto com o funcionamento das instituições públicas generalizou-se a partir das experiências continuadas de corrupção, engessamento do sistema de partidos políticos, e outros déficits de desempenho institucional. Aonde as instituições respondem melhor à sua missão original, como na Holanda, Noruega, Finlândia e Dinamarca, a confiança dos cidadãos 
é mais alta, mas também oscila. A variação realmente dramática ocorreu nas democracias mais antigas como Estados Unidos, Inglaterra, França, Suécia e Canadá, onde pesquisas realizadas por mais de quatro décadas mostraram que a confiança em autoridades e em instituições públicas caiu sistematicamente, nos últimos 30 anos, invertendo a tendência de prosperidade econômica associada à tranqüilidade política dominante entre o fim da II Guerra Mundial e os anos 60 . Enquanto naquele período cerca de $3 / 4$ de cidadãos dos países mencionados mostravam-se satisfeitos, deferentes e confiantes em governos, instituições e burocracias públicas, na atualidade apenas $25 \%$ expressam essa atitude, reagindo criticamente a crises, escândalos e, principalmente, à deterioração do padrão de funcionamento das instituições. Nesses casos, as mudanças afetaram o comportamento dos cidadãos quanto a mecanismos básicos da democracia representativa como partidos e eleições. Caíram as taxas de 74 identificação partidária, a mobilização dos eleitores por partidos, o comparecimento em eleições e o interesse por política nos Estados Unidos, Inglaterra e boa parte da Europa continental.

A situação dos regimes políticos nascidos da "terceira onda de democratização", nos termos de Samuel Huntington, é mais preocupante, embora tenha especificidades próprias. Enquanto em vários países do Leste Europeu a avaliação do regime democrático ainda não tinha ultrapassado, no início dos anos 90, os índices favoráveis ao regime anterior, em boa parte dos países latino-americanos - onde a tradição democrática é sabidamente frágil e descontínua - apenas cerca de $1 / 5$ do público têm 'muita' ou 'alguma' confiança em parlamentos e partidos políticos, e menos de 1/3 confia em governos, funcionários públicos, polícia ou judiciário. As pesquisas relatadas no livro do autor Os Brasileiros e a Democracia, do início dos anos 90, mostraram isso para o Brasil, e os livros Ciudadanía y Cultura Política, de Vic- 
tor Manuel Durand (2004) sobre o México; e Chile, un país dividido, de Carlos Huneeus (2003), também associaram os sentimentos de apatia ou de impotência política com a desconfiança dos cidadãos de instituições democráticas. Não é diferente a situação da Coréia do Sul estudada por Doh C. Shin (2005). As instituições democráticas nasceram a partir da estrutura autoritária, em boa parte desses casos, muitas vezes não são coerentes com seus objetivos e, mesmo reformadas, não tiveram ainda oportunidade de passar pelo processo de rotinização que, no caso das democracias mais antigas, malgrado seu mal-estar recente, foi um ingrediente importante de seu processo de consolidação originária.

É verdade que em todos esses casos não existem sinais de preferência por um regime antidemocrático, mas a desconfiança dos cidadãos de instituições públicas aponta para um paradoxo cujos efeitos para a continuidade da democracia em longo prazo precisam ser mais bem conhecidos e estudados. É razoável supor que a democracia pode conviver indefinidamente com o descrédito dos cidadãos em normas, procedimentos e instituições que, por definição, têm a função de mediar a competição de interesses divergentes e, ao mesmo tempo, promover a coordenação e a cooperação sociais necessárias ao funcionamento das sociedades complexas? A continuidade do regime no tempo é suficiente para dirimir os efeitos da desconfiança política? E como avaliar a qualidade de um regime cujos mecanismos básicos de funcionamento suscitam tanta dúvida entre os cidadãos, como é o caso das instituições democráticas? Para responder a essas questões são necessários três argumentos. Em primeiro lugar, é preciso definir como o conceito de cidadania deve ser abordado contemporaneamente a partir da controvérsia entre a concepção liberal clássica, para a qual a cidadania é essencialmente um status jurídico e administrativo formal, e a crítica comunitarista que pretende resgatar a noção cívico-republicana do tema. Em segundo lugar, 
é necessário enfrentar a premissa das teorias democráticas originárias de que o risco de abuso do poder supõe desconfiança e não confiança nas instituições. E, finalmente, admitida a relevância da confiança política, é preciso examinar, contra a tendência usual que leva a vê-lo como um fenômeno de face única, a sua natureza multidimensional e as implicações que isso tem para a pesquisa e o avanço do conhecimento.

\section{A Questão da Cidadania}

A palavra cidadão provém do termo latino civitas, mas como observaram vários autores, suas fontes intelectuais encontram-se nas religiões da Antigüidade e na civilização greco-romana, cujo legado remete às noções de liberdade, igualdade e virtudes republicanas. As referências à idéia abstrata de igualdade já estavam presentes em textos religiosos antigos para os quais todo ser humano tinha status igual diante de Deus. Mas foi na Antigüidade grega que os conceitos de igualdade e liberdade adquiriram relevância no contexto da pólis, isto é, da cidade protegida da hostilidade de vizinhos ou estrangeiros, cujos laços de lealdade e de identidade de seus cidadãos formavam a base da comunidade voltada para o bem público. Mais tarde, no período medieval, o burgo ocupou o lugar da pólis, dando novas dimensões à idéia de liberdade, e o burguês converteu-se no protótipo do cidadão, sendo a cidade o seu habitat natural. Na continuidade dessa tradição, nos séculos XVII e XVIII, o contratualismo de J. Locke e de J. J. Rousseau forneceu as bases filosóficas do conceito de cidadania do liberalismo e as revoluções inglesa, americana e francesa validaram seu uso ao estabelecer um vínculo jurídico-legal entre as noções de liberdade, igualdade, fraternidade e o Estadonação. O cidadão passou a ser visto como detentor de um status formal que reconhecia o seu pertencimento à comunidade política nacional e, ao mesmo tempo, assegurava 
o seu direito de participar da escolha de governos e de representantes.

A concepção liberal clássica está baseada em uma perspectiva protetora do cidadão como membro da associação política. O objetivo principal é proteger o indivíduo de riscos de arbitrariedade, opressão ou violação de seus direitos por parte seja de quem exerce o poder, seja dos outros indivíduos. Locke formulou essa concepção de proteção em termos do direito natural à vida, à liberdade e à propriedade. Por isso, as liberdades modernas são entendidas como negativas, isto é, como mecanismos que institucionalizam a ausência de coerção para evitar que o indivíduo seja impedido de realizar os seus interesses. Associado com essa concepção, o modelo de democracia minimalista supõe uma estrutura jurídico-legal que assegura a separação de poderes, o funcionamento do sistema de representação, a obrigação de obediência às leis e, finalmente, o direito de participar da escolha da elite governante - que M. Weber (1974) e J. Schumpeter (1975) viram como o principal objetivo da democracia. Em consonância com essa concepção, teóricos do pluralismo como Robert Dahl (1966) e Norberto Bobbio (1984) deslocaram, contudo, o foco da análise do indivíduo para o papel de facções, grupos de pressão e de interesses na competição política, mostrando que sem o reconhecimento da diversidade política não existe democracia. O modelo protetor e minimalista da democracia, baseado no princípio normativo da igualdade formal dos cidadãos perante a lei, supõe que as diferenças de posses materiais, poder ou status social não eliminam a igualdade diante da lei, fundamento da igualdade de direitos, em especial, do direito de voto. Mas a igualdade não é um fim em si, destinado a fundar uma comunidade de interesses, mas instrumento de proteção do indivíduo contra a opressão e a injustiça. Diante disso, a objeção de K. Marx e de seus seguidores é que a noção de cidadania centrada nas formalidades jurídi- 
co-legais ocultas, a exclusão e a desigualdade real geradas pelas relações capitalistas. Marshall (1965), em sua celebrada conferência sobre o tema, reconheceu isso ao designar como uma espécie de "guerra" o processo contínuo de conquistas de direitos de cidadania verificado desde o século XVIII na Inglaterra. Mas mesmo autores como John Rawls (1971), preocupados com as exigências de justiça do sistema de cidadania, vêem os cidadãos usando os seus direitos essencialmente para alcançar os seus interesses próprios. Embora isto deva se dar no contexto de constrangimentos impostos pela exigência de respeito aos direitos dos outros, a sua ênfase é a defesa do "direito dos indivíduos de definir, revisar e buscar racionalmente seus interesses privados e sua concepção particular de bem", e não a participação dos cidadãos para a consecução do bem público como suposto pela concepção clássica de cidadania.

É precisamente sobre isso que incide a crítica de comunitaristas como Sheldon Volin (1992) e Michael Sandel (1982). Segundo eles, a tradição liberal relegou as preocupações normativas da política ao campo da moralidade privada. A política teria sido destituída do seu componente ético - associado na concepção cívico-republicana com o desenvolvimento das virtudes requeridas pela participação na pólis e na república - para assumir uma concepção essencialmente instrumental, voltada apenas para a realização de interesses privados definidos independentemente da discussão pública. Isso teria esvaziado a noção de cidadania baseada na propensão natural dos cidadãos de juntar-se com os seus iguais para definir a ação coletiva necessária à realização do bem almejado pela comunidade política, e teria dado origem a uma noção descomprometida do ser político, empobrecedora da cidadania como comunidade constitutiva, cujo processo de definir objetivos comuns seria o fundamento da identidade política dos indivíduos. Segundo os comunitaristas, a concepção liberal apenas reconhece o surgimento 
de uma comunidade instrumental em que os indivíduos participam com interesses e identidades previamente constituídos, sem vínculo ou raiz social, o que minimiza a importância da esfera pública para o desenvolvimento das virtudes cívicas necessárias ao funcionamento do bom governo.

Diante de tais limites, os comunitaristas advogam o retorno da visão cívico-republicana de bem público como algo anterior e independente dos interesses individuais. Essa visão, quase suprimida do debate político contemporâneo, inspira-se na tradição greco-romana, na experiência das repúblicas italianas da Idade Média e no pensamento republicano inglês do século XVII. O valor fundamental da atividade política, para ela, é a busca do bem comum concebido como uma dimensão que se sobrepõe aos interesses privados - como também reivindicou Rousseau com a sua noção de vontade geral -, e só alcançáveis pela participação direta e ativa dos cidadãos no processo de tomada de decisões coletivas, e não pela representação. Vista como fim em si, a participação dos cidadãos é a fábrica a partir da qual se desenvolve a comunalidade necessária ao advento do governo virtuoso, e a liberdade, mais do que efeito da limitação dos excessos do governo ou da avidez dos outros cidadãos, é a condição de seu compromisso com o bem público - entendido como expressão dos interesses de todos.

Essa visão implica em um modelo de cidadania mais ativa, com vantagens para a educação e a formação de cidadãos participantes e responsáveis diante das exigências da vida pública, mas ela padece de uma séria limitação, pois retoma uma noção pré-moderna da política ao advogar uma concepção essencialista de bem comum que, por definição, exclui a divergência de interesses e o conflito inerente à disputa em torno da boa vida e do bom governo. A concepção da comunidade política organizada em torno de uma idéia única de bem público é incompatível com a natureza da sociedade moderna e com as conquistas da revolução demo- 
crática como as liberdades individuais, o reconhecimento do pluralismo e a noção de sociedade civil como expressão da diversidade de interesses que dá origem a objetivos políticos divergentes. O risco representado por essa idéia de bem comum é a substantivação do processo político, e a desqualificação da natureza conflitual da política moderna. A grande novidade da democracia, como argumentou Claude Lefort, foi a dissolução dos marcos de certeza que articulavam as crenças sobre o mando e a obediência nas sociedades tradicionais, e a alocação da disputa pelo poder - considerado como um espaço vazio - em um terreno de indeterminação que é incompatível com a idéia de garantia final de resultados ou a noção substantiva do bem comum. A democracia supõe incertezas, especialmente, quanto aos objetivos que as sociedades escolhem para resolver os seus dilemas coletivos.

Em face dos limites tanto do modelo liberal como da concepção comunitarista, autores como Chantal Mouffe (1992) e Jean Leca (1992) argumentaram recentemente que uma concepção de cidadania adequada às exigências das sociedades complexas contemporâneas - desiguais, diferenciadas e reestruturadas por novos processos de produção e comunicação derivados da globalização - tem de articular as conquistas da revolução democrática dos três últimos séculos com aspectos da tradição cívico-republicana. Essa nova concepção tem de incorporar simultaneamente, em um mesmo movimento constitutivo, a prioridade dos direitos individuais sobre a noção de um bem comum substantivo e a importância da idéia de inserção dos indivíduos na comunidade política em decorrência de seu interesse de associar-se para agir e participar do processo de tomada de decisões públicas. A dimensão pública que corresponde a essa concepção refere-se não a um projeto essencialista que estipula previamente os resultados da competição política, mas ao processo de construção da ação política como res- 
posta a dilemas coletivos reconhecidos como tal pela comunidade política. O que os cidadãos compartilham não é a presunção de consenso prévio ou uma visão homogênea quanto à solução dos conflitos em jogo, mas o compromisso derivado da decisão de reconhecer como legítimas as suas diferenças e de associar-se em função de sua decisão de agir em comum para alcançar objetivos públicos. Esse compromisso envolve a aceitação de princípios como a liberdade e a igualdade, decorrentes das transformações democráticas e, ao mesmo tempo, estabelece as bases das relações de lealdade entre atores que, por circunstância ou por escolha, estão associados entre si. Essa lealdade os une e funda as bases da noção de direitos de cidadania que se refere, não apenas a diferenças de status político ou social, mas à diversidade de identidades derivadas de relações de gênero, raça, etnia, religião ou cultura.

A idéia - que Mouffe toma emprestada do filósofo inglês Michael Oakeshott (1975) - supõe que essa associação envolve uma prática comum, através da qual seus membros definem condições específicas para realizar o seu compromisso público. Essa prática cívica, designada como república, mais do que definir fins últimos da ação dos cidadãos, estabelece as regras e as práticas que eles aceitam subscrever para agir em comum. Como a ação coletiva em tais condições envolve, por definição, a divisão e o antagonismo próprios da política moderna, essas condições incluem um complexo de normas, procedimentos e instituições, cujo objetivo é regular o modo dos cidadãos reconhecerem e resolverem as suas diferenças e, ao mesmo tempo, oferecerem as bases do julgamento político que fazem ao participar da realização de objetivos coletivos. Trata-se de uma associação política de que participam atores de diferentes orientações que, a despeito de também pertencerem às associações correspondentes aos seus interesses particulares, como partidos, grupos de pressão ou corporações, não estão em conflito com sua 
decisão de integrar a comunidade política mais abrangente. Ou seja, a sua identidade como cidadãos pertencentes à república decorre da comunalidade expressa pela definição e pela adoção de regras de intercurso civil que organizam suas relações políticas. Oakeshott enfatiza o caráter ético e moral - não instrumental - da adesão dos cidadãos a essas regras, mas isso se refere menos a uma visão abrangente da finalidade da sociedade, e mais às propriedades e à qualidade do código ético-político que norteia a mediação e a regulação da disputa por interesses políticos divergentes. Nessa visão, diferente de concepções tradicionais sobre o papel do Estado, a autoridade pública não é um instrumento neutro de conciliação de interesses, nem o comitê executivo dedicado à promoção de interesses particulares, mas a esfera que autoriza, segundo regras específicas, que esses interesses participem da disputa política, normatizando o modo dessa disputa se dar. Diferente também da concepção usual, de que o império da lei é suficiente para legitimar a associação política necessária à garantia da liberdade e da igualdade, importa agora o conteúdo normativo de regras e instituições adotadas e isso, em última análise, está no centro da relação entre cidadãos e a esfera pública; está no centro e define a natureza dessas relações.

\section{A Questão da Confiança}

Em linguagem comum, confiança designa segurança de procedimento ou crença em outros com quem interajo e convivo. Nas ciências sociais, o interesse pelo conceito está associado à preocupação com os processos informais através dos quais as pessoas enfrentam incertezas e imprevisibilidades decorrentes da crescente complexificação da vida que caracteriza o mundo globalizado, interdependente e crescentemente condicionado por avanços tecnológicos. Essa situação implica em conhecimento limitado sobre os processos de tomada de decisões coletivas e as ações de 
governos que afetam a vida das pessoas. Diante disso, como mostraram autores como N. Luhmann (1979), A. Giddens (1990) e C. Offe (1999), a velha demanda por coordenação social que está na origem do Estado moderno se re-atualizou na época contemporânea, associando-se com a demanda por cooperação social, mas para deixarem-se coordenar e cooperar as pessoas precisam ter capacidade de previsão sobre o comportamento dos outros e sobre o funcionamento de regras, normas e instituições que condicionam esse comportamento - cujos efeitos afetam a sua vida.

Autores de diferentes orientações argumentam que a confiança é a resposta para essa situação e, nas últimas décadas, o conceito vem sendo usado para designar grande variedade de fenômenos sociais e políticos que, malgrado colocar os atores envolvidos em situação de risco, se refere à coesão social necessária ao funcionamento das sociedades complexas, desiguais e diferenciadas. Parte da controvérsia tratou da relação entre os conceitos de confiança interpessoal e confiança política, abordada por diferentes enfoques tanto dos racionalistas, como dos cultores dos modelos de "cultura cívica" de Almond \& Verba (1965), "capital cultural" de Bourdieu, "capital social" de Putnam (1993), "pósmaterialismo" de Inglehart (1997) e "cidadãos críticos" de Pippa Norris (1999) e Dieter Klingemann (1998), mas a discussão envolve bem mais do que isso.

Para os racionalistas, a confiança interpessoal envolve a expectativa racional de A (o confiante) sobre o curso de ações a ser adotado por B (o confiado). Diante da imprevisibilidade humana, isto é, do fato do comportamento alheio não poder ser completamente controlado - a não ser em situações-limite -, a situação implicaria em risco de dano ou de vulnerabilidade de A diante de B. Como o ato de confiar é insuficiente para determinar o resultado final da interação, autores como Russell Hardin supõem que só não existe abuso de confiança se a relação encapsular os interesses das 
partes. Ou seja, quando quem confia tem segurança sobre a motivação solidária do confiado, sabendo que seus interesses serão levados em consideração por ele. A confiança interpessoal abrangeria, então, as situações em que interesses mútuos, que geram benefícios comuns e eliminam os danos derivados de abuso da confiança, podem ser mobilizados, mas fora disso, a confiança seria injustificável do ponto de vista racional.

Os críticos dessa perspectiva sustentam, no entanto, que essa situação está longe de ser a mais comum, não sendo sempre racional a decisão de confiar, nem se determinando exclusivamente - como no caso de uma decisão baseada no cálculo de custos/benefícios - pelo nível de informação disponível a respeito do comportamento dos outros, pois os indivíduos têm capacidade cognitiva limitada para acessar, na quantidade e na qualidade necessárias, as informações adequadas para avaliar a conduta alheia ou a utilidade da interação em que estão envolvidos. A eficiência, a pluralização e a mobilidade social típicas das sociedades contemporâneas ampliam as possibilidades de escolha dos indivíduos, mas a complexidade social e política inerente à tomada de decisões coletivas limitam sua capacidade de controlar a informação necessária para que suas decisões sejam compatíveis com seus interesses e aspirações.

A confiança preencheria, então, o vazio deixado pela impossibilidade das pessoas mobilizarem os recursos cognitivos requeridos para avaliar as suas habilidades e julgar as decisões políticas que afetam suas vidas. Com base em premissas de A. de Tocqueville (1969) e de G. Almond \& S. Verba (1965), autores como R. Putnam (1993) e R. Inglehart (1997) argumentaram que a confiança interpessoal ou social se explica a partir do contexto sócio-cultural que a origina. Sua ocorrência, baseada na experiência social e em valores compartilhados, favorece a disposição das pessoas para agir em comum e a acumulação de capital 
social resultante disso levaria à acumulação de capital político favorável ao funcionamento do regime democrático. $\mathrm{O}$ fato das pessoas confiarem umas nas outras estimularia a cooperação e favoreceria o surgimento de virtudes cívicas, reforçando a capacidade dos grupos envolvidos de obter benefícios comuns desejados.

Mas a questão não é tão simples. A premissa de que a confiança social gera a confiança política tem de enfrentar a objeção segundo a qual a democracia nasceu da desconfiança de que quem tem poder não é confiável, e de que os procedimentos habituais usados para mantê-lo precisam ser controlados para se evitar seu abuso. Segundo essa concepção, a vantagem da adoção de regras e instituições democráticas está no controle, limitação e distribuição do poder propiciado por elas. A inovação democrática consistiu em criar normas de procedimento para colocar em cheque os poderes discricionários implícitos nas relações de poder. Em conseqüência, a democracia implica em supervisão e monitoramento do exercício do poder pelos cidadãos. $\mathrm{Ou}$ seja, ela implica em desconfiança e, para fazer valer isso, opera com normas e instituições desenhadas para que os riscos de origem possam ser controlados. Nesse caso, como falar em confiança política?

O argumento de C. Offe (1999), M. Warren (1999) e P. Sztompka (1999) a favor da confiança inverte as formulações anteriores. A idéia é precisamente que, na impossibilidade de garantia absoluta de que o conflito de interesses divergentes possa ser resolvido pacificamente, a democracia moderna institucionaliza regras, normas e instituições que asseguram um padrão civilizado de competição política, algo sugerido também por autores como Mouffe (1992) e Oakeshott (1975). Mecanismos como eleições, representação, liberdade de expressão e de associação, direito de julgamento justo e imparcial, separação de poderes e a obrigação de prestação de contas por governos capacitam os cidadãos 
para desafiar as relações de que desconfiam, mas para fazer isso, a sua desconfiança precisa ser "institucionalizada", ou seja, tornada permanente através de regras que, uma vez mobilizadas, asseguram que eles podem competir por seus interesses sem risco para sua liberdade e para seus direitos. A idéia é que os direitos sejam "naturalizados" pelas instituições e "internalizados" na ordem institucional. Mas para isso, os cidadãos precisam aceitar que as regras garantem o seu direito de controlar as circunstâncias que geram desconfiança. Ou seja, a institucionalização da desconfiança supõe a existência de uma cultura de confiança para funcionar e são as instituições democráticas que tornam isso possível. Nesse sentido, Sztompka (1999) fala pelo menos de cinco práticas democráticas que requerem a confiança para operar com sucesso. A primeira é a comunicação entre os cidadãos com vistas à definição de objetivos públicos; a segunda é a prática da tolerância e a aceitação do pluralismo; a terceira é o consenso mínimo sobre o funcionamento dos procedimentos democráticos; a quarta é a civilidade requerida pela relação de atores que competem por objetivos diferentes; e, a última, é a participação dos cidadãos seja em associações da sociedade civil, seja em organizações de objetivos políticos. Todas são indispensáveis à democracia e todas requerem graus razoáveis de confiança para funcionar.

Mas o argumento de Offe (1999) é mais complexo. Para ele, com a crescente interdependência dos sistemas complexos que constituem as sociedades contemporâneas, o Estado assumiu funções de articulador, não mais e nem exclusivamente de responsável pela solução de problemas coletivos que, antes, eram enfrentados também pela iniciativa espontânea da sociedade civil. Ao mesmo tempo, diante das transformações provocadas pela globalização e pela pressão para diminuir seu papel de ator direto na esfera econômica e social, o Estado fragilizou-se e, para implementar suas políticas, tem de apoiar-se na cooperação social. A idéia é 
que a coordenação social necessária à implementação de objetivos que interessam a todos demanda o envolvimento dos cidadãos, quando menos, para garantir que as instituições cumpram a missão para a qual existem, e isso implica em confiança nas mesmas. Mas confiar em instituições não é a mesma coisa que confiar em pessoas de quem se pode esperar reciprocidade, indiferença ou hostilidade. Em contraste com Hardin, para quem a inexistência de confiança em instituições é resultado da informação limitada de que dispõem os indivíduos, Offe (1999) põe o foco da análise nos recursos éticos e normativos das instituições, retomando em outro contexto premissas propostas por Oakeshott (1975). Confiar em instituições supõe conhecer a idéia básica ou a função permanente atribuída a elas pela sociedade, a exemplo da crença de que a polícia existe para garantir a segurança das pessoas. Isso se explicita através das regras constitutivas das instituições que remetem a conteúdos éticos e normativos resultantes da disputa dos atores pelo sentido da política; por isso, essas regras são referências tanto da ação dos responsáveis pelas instituições como das pessoas comuns que se orientam, a partir de sua experiência, por aquilo que aprendem sobre o funcionamento das instituições.

Isso significa - como também argumentam Mouffe (1992) e Oakeshott (1975) - que as instituições não são neutras, mas mecanismos de mediação política informados por valores derivados das escolhas que a sociedade faz para enfrentar seus desafios políticos. A confiança política dos cidadãos não é, portanto, cega ou automática, mas depende das instituições estarem estruturadas para permitir que eles conheçam, recorram ou interpelem os seus fins últimos fins aceitos e desejados pelos cidadãos. Regras institucionais democráticas como a imparcialidade em eleições, a probidade no uso de recursos públicos ou a igualdade de acesso à justiça, ao "naturalizar" os direitos de cidadania, geram as expectativas sociais sobre seu desempenho, assim como de 
seus funcionários, e isso afeta a relação dos cidadãos com elas. Ou seja, a confiança política dos cidadãos depende da coerência das instituições a respeito de sua justificação normativa, e é o repertório de significações resultante de seu funcionamento que determina a medida dessa confiança, que pode ou não se estender aos seus responsáveis, conforme seu comportamento seja compatível com aqueles objetivos. Essa dinâmica envolve, portanto, a experiência dos cidadãos com as instituições e isso conta para a ocorrência do fenômeno de confiança.

\section{Um Conceito Multidimensional}

A abordagem proposta retoma uma idéia original de David Easton (1965) que, analisando a natureza do apoio público aos sistemas políticos, meio século atrás, falou de apoio específico e de apoio difuso como dimensões diferentes. Enquanto o primeiro se refere à satisfação dos cidadãos com o desempenho de governos e de lideranças políticas, o apoio difuso diria respeito à sua atitude em relação ao sistema político como um todo, independentemente do desempenho de seus responsáveis.

Easton argumentou que o apoio político está relacionado com a experiência das pessoas. Os cidadãos se identificam com as instituições porque aprendem a fazê-lo através de processos sucessivos de transmissão de seu significado para as diferentes gerações, mas principalmente, porque as suas experiências políticas, ao longo de sua vida adulta, qualificam-nos para avaliar racionalmente o seu desempenho. A participação em eleições e a vivência de processos institucionais que ampliam ou restringem o seu acesso a direitos estabelecidos por lei fornece as bases do seu julgamento. Essa avaliação inclui a percepção de resultados viabilizados pela ação das instituições, a exemplo de avanços nas áreas sociais e econômicas, mas também do cumprimento da missão normativa atribuída às instituições pela sociedade. As pes- 
soas aprendem a distinguir entre as diferentes dimensões envolvidas no processo e, uma vez que isso se torne parte de sua rotina, elas passam a diferenciar a ação de governos do desempenho específico de instituições. Isso se refere às esferas de ação governamental, a serviços públicos e a instituições específicas que, a exemplo do judiciário, simbolizam o acesso dos cidadãos a direitos estabelecidos por lei.

Em conseqüência disso, o apoio público às instituições políticas não pode ser visto como um fenômeno unidimensional, mas como algo de face múltipla que explicita para os cidadãos as qualidades da ação institucional. As diferentes dimensões institucionais não podem ser confundidas sob pena de ocultamento da realidade e, por essa razão, partindo da observação de Easton, alguns autores refinaram o foco da análise através da inclusão de novas dimensões no escopo das pesquisas empíricas do tema. Identificaram cinco níveis de confiança política que, embora relacionados, tem de ser pesquisados separadamente: na comunidade política per se, nos princípios do regime democrático, no desempenho específico do regime, nas instituições democráticas e nos atores políticos. O primeiro nível refere-se ao modo pelo qual os cidadãos se vinculam ao Estado-nação, isto é, às fronteiras territoriais e políticas que, malgrado os limites introduzidos pela globalização, continuam sendo o parâmetro de definição da sua identidade coletiva. O segundo nível alude à adesão dos cidadãos ao regime democrático como um ideal, isto é, aos valores como a liberdade, o império da lei, a participação, a tolerância, etc., que, mesmo não expressando um consenso absoluto, opõem a democracia a outros regimes políticos. O terceiro nível refere-se ao desempenho concreto do regime democrático no dia-a-dia em contraste com o seu significado ideal. O quarto nível refere-se ao funcionamento especializado das instituições democráticas e abrange as percepções dos cidadãos quanto ao papel de parlamentos, partidos políticos, executivo, 
judiciário, sistema legal e etc. O último nível diz respeito ao apoio a líderes e membros do segmento que se convencionou chamar de classe política. Essa discriminação de níveis empíricos distintos permite explorar analiticamente o fato das pessoas experimentarem e confiarem de modo desigual em diferentes dimensões institucionais, excluindo a hipótese simplista de que a confiança em um nível implica necessariamente em confiança em outro. Isso permite explicar, por exemplo, porque indivíduos que valorizam positivamente o regime democrático, avaliam negativamente o funcionamento das instituições públicas, como ocorre em muitas das novas democracias.

Nas duas últimas décadas, Pippa Norris (1999) e seus colaboradores retomaram a contribuição de Easton (1965). Segundo eles, os sentimentos gerados a partir da experiência institucional dos cidadãos referem-se, fundamentalmente, ao jogo proporcionado pelas regras constitucionais vigentes, escritas ou não, que resultam na interação entre ganhadores e perdedores do processo político-institucional. Nesse sentido, as experiências de derrotas e vitórias de partidos políticos, grupos de interesse ou associações civis, ao longo do tempo, com o executivo, o legislativo e o judiciário influenciam as atitudes políticas dos cidadãos. As pessoas tendem a apoiar as instituições se as regras do jogo asseguram que o partido de sua preferência chegue ao poder, mas a capacidade da ordem institucional de absorver e processar as suas demandas, mesmo se não adotadas de imediato, também conta. Em sentido contrário, uma eventual sucessão de derrotas do partido político de preferência dos cidadãos ou a impermeabilidade de governos, legislativos ou tribunais de justiça às suas demandas por direitos indicam que seu poder de influir sobre o processo decisório não existe, provocando frustração, desconfiança e a crítica das instituições.

A idéia é que arranjos constitucionais que maximizam as oportunidades dos ganhadores produzem níveis mais altos 
de confiança institucional e Norris, baseando-se nos resultados de pesquisas empíricas realizadas em 25 democracias, demonstrou que existe associação significativa entre a desconfiança em instituições democráticas e o mau funcionamento de regras institucionais, liberdades civis e direitos políticos - cujo objetivo, em última análise, é facilitar a inclusão política e ampliar o acesso às oportunidades do sistema democrático. O diagnóstico confirma os resultados de estudos de Donatella Della Porta (2000) e de Susan Pharr (2000), segundo os quais a deterioração da imagem das instituições democráticas em países como a Itália e o Japão, nas últimas décadas, está diretamente relacionada com práticas de corrupção, de malversação de fundos públicos e com o déficit de funcionamento dos sistemas de partidos e de representação política. O cenário oferece um paralelo com a experiência vivida, nas últimas décadas, por várias das novas democracias latino-americanas.

Em conjunto, esses estudos confirmam a tese de que as experiências dos cidadãos que influem sobre a confiança política estão associadas com a vivência de regras, normas e procedimentos que decorrem do princípio de igualdade de todos perante a lei. Mas elas também mostram que a avaliação dos cidadãos sobre as instituições depende do aprendizado propiciado a eles pelo funcionamento daquelas. Uma vez que sejam capazes de sinalizar, de modo inequívoco, o universalismo, a imparcialidade, a justeza e a probidade de seus procedimentos, assegurando que os interesses dos cidadãos são efetivamente levados em conta pelo sistema político, as instituições geram solidariedade e ganham a confiança dos cidadãos. Em sentido contrário, quando prevalece a ineficiência ou a indiferença institucional diante de demandas para fazer valer direitos assegurados por lei ou generalizam-se práticas de corrupção, de fraude ou de desrespeito ao interesse público, instala-se uma atmosfera de suspeição, de descrédito e de desesperança, comprome- 
tendo a aquiescência dos cidadãos à lei e às estruturas que regulam a vida social; floresce, então, a desconfiança e o distanciamento dos cidadãos da política e das instituições democráticas, a exemplo da experiência brasileira recente.

Uma vantagem evidente da perspectiva proposta sobre as abordagens tradicionais do tema é que a explicação da confiança política radica nas próprias instituições e não em outros fatores. Mas longe de sugerir uma perspectiva institucionalista desenraizada de seu contexto social, a ênfase posta na experiência dos cidadãos com as instituições restabelece a relação entre as dimensões micro e macro da política, ou seja, reconhece que as atitudes individuais afetam e são afetadas pelo desempenho das instituições. Mais ainda, ao colocar a sua ênfase na significação normativa das instituições, tanto nos objetivos éticos e políticos atribuídos a elas pela sociedade, como nos seus modos concretos de mediar a competição política, a abordagem proposta retoma o sentido de comunalidade associado com o compromisso dos cidadãos de participar da vida pública e, nessa medida, recupera a identificação racional dos interesses dos indivíduos com aqueles da cidadania através da mediação institucional.

Não se trata de que as instituições induzem simplesmente à realização de interesses privados - e, mais uma vez, separe os indivíduos da comunidade -, mas, nas condições da mediação institucional escolhida pela sociedade para enfrentar os seus dilemas, que coloquem esses interesses em sintonia e cooperação com as exigências dos interesses públicos. Essa abordagem retoma a formulação de Tocqueville sobre o "interesse bem compreendido", mas isso é algo que merece tratamento em outro artigo.

\section{José Álvaro Moisés}

é professor do Departamento de Ciência Política da USP 
José Álvaro Moisés

\section{Referências Bibliográficas}

ALMOND, G.; VERBA, S.. The civic culture: Political attitudes and democracy in five nations. Boston: Little Brown, 1965.

BENDIX, R.. Nation-building and citizenship. Berkeley: University of California Press, 1977.

BOBBI0, N.. O futuro da democracia: Uma defesa das regras do jogo. Rio de Janeiro: Paz e Terra, 1984.

CARVALHO, J. M.. Cidadania no Brasil: O longo caminho. Rio de Janeiro: Civil, Brasileira, 2002.

DAHL, R.. Political oppositions in western democracias. New Haven: Yale University Press, 1966.

DURAND PONTE, V. M.. Ciudadanía y Cultura Política: México 1993-2001. México D. F.: Siglo Veintiuno Ed., 2004.

EASTON, D.. A system análisis of political life. Nova York: Wiley, 1965.

GIDDENS, A.. The consequences of modernity. Stanford: Stanford University Press, 1990.

HARDIN, R.. "Do we want trust in government?" In: WARREN, M.. Democracy and trust. Cambridge: Cambridge University Press, 1999.

HUNEEUS, C.. Chile, un país dividido. Santiago: Catalonia, 2003.

INGLEHART, R.. "The erosion of institutional authority and post-materialist values”. In: NYE, S. J.; ZELIKOW, P. D. E.; KING, D. C. (eds.). Why people don't trust government. Cambridge, Mass.: Harvard University Press, 1997. KLINGEMANN, H-D.; FUCHS, D.. Citizens and the state. Oxford: Oxford University Press, 1998.

LECA, J.. "Questions on Citizenship”. In: MOUFFE, C.. Dimensions of radical democracy. Londres: Verso, 1992.

LEVI, M.; BRAITHWAITE, V.. Trust and governance. Nova York: Russell Sage Foudation, 1998.

LUHMANN, N.. Trust and power. Nova York: Wiley, 1979.

MARSHALL, T. H.. Class, citizenship and social development. Nova York: Doubleday, 1965.

MOISÉS, J. A.. Os brasileiros e a democracia - Bases sócio-políticas da legitimidade democrática. São Paulo: Ática, 1995.

MOUFFE, C.. "Democratic citizenship and the political community". In: MOUFFE, C. Dimensions of radical democracy: Pluralism, citizenship and community. London: Verso, 1992.

NORRIS, P.. Critical citizens: Global support for democratic government. Oxford: Oxford University Press, 1999.

NYE, J. S.; ZELIKOW, P. D.; KING, D. C.. Why people don't trust government. Cambridge, Mass.: Harvard University Press, 1997. 
OAKESHOTT, M.. On human conduct. Oxford: Oxford University Press, 1975. OFFE, C.. "How can we trust our fellow citizens?". In: WARREN, M.. Democracy and trust. Cambridge: Cambridge University Press, 1999.

PHARR, S. J.. "Official's misconduct and public distrust: Japan and the trilateral democracies”. In: PHARR, S. J.; PUTNAM, R.. Disaffected democracies: What's troubling the trilateral countries? Princeton, New Jersey: Princeton University Press, 2000.

PORTA, D. D.. "Social capital, beliefs in government and political corruption”. In: PHARR, S. J.; PUTNAM, R.. Disaffected democracies: What's troubling the trilateral countries? Princeton, New Jersey: Princeton University Press, 2000.

PUTNAM, R.. Making democracy work. Princeton: Priceton University Press, 1993.

RAWLS, J.. A theory of justice. Oxford: Oxford University Press, 1971.

REIS, E. P.. Processos e escolhas: Estudos de sociologia política. Rio de Janeiro: Contracapa, 1998.

SANDEL, M.. Liberalism and the limits of justice. Cambridge: Cambridge University Press, 1982.

SCHUMPETER, J. A.. Capitalism, socialism and democracy. Nova York: Harper Torchbooks, 1975.

94 SHIN, D. C.. Popular support for democracy and institutional trust in Korea. 2005. (Original não publicado.)

SZTOMPKA, P.. Trust - A sociological theory. Cambridge: Cambridge University Press, 1999.

TOCQUEVILLE, A.. A democracia na América. São Paulo: Edusp, 1969.

WARREN, M.. Democracy and trust. Cambridge: Cambridge University Press, 1999.

WEBER, M.. Ensaios de sociologia e outros escritos. São Paulo: Abril Cultural, 1974.

WOLIN, S.. "What revolutionary action means today?". In: MOUFFE, C.. Dimensions of radical democracy. Londres e Nova York: Verso, 1992. 


\section{PARTE I}

\section{CIDADANIA, CONFIANÇA E INSTITUIÇÕES DEMOCRÁTICAS}

JOSÉ ÁLVARO MOISÉS

$\mathrm{O}$ artigo analisa três questões pendentes no debate sobre a relação entre confiança e instituições democráticas: 1) Qual a correta aproximação ao conceito de cidadania, tendo em conta a controvérsia entre a visão liberal clássica e a comunitarista?; 2) O que dizer da premissa das teorias democráticas tradicionais, de que o abuso do poder político requer a desconfiança, e não a confiança, das instituições?; 3) Admitida a importância da confiança, que vantagens poderíamos extrair ao pensarmos o fenômeno como de natureza multidimensional, contra a tendência usual de vêlo como um fenômeno de face única?

Palavras-chave: Confiança; Instituições Democráticas;

Cidadania; Liberalismo; Comunitarismo.

\section{CITIZENSHIP, TRUST AND DEMOCRATIC INSTITUTIONS}

The article analyses three issues around the debate on the relationship between trust and democratic institutions: 1) what is the right approach to the concept of citizenship, considering the controversy between the classic liberal conception and the comunitarist one?; 2) what to say about the traditional democratic theories's premises, that we should expect from the citizens distrust rather than trust, if we want to keep political power in its proper limits; 3) if we admit trust, how our knowledge of it could be enhanced in seeing it as a many-dimensional, instead of one-dimensional, phenomenon?

Keywords: Trust; Democratic Institutions; Citizenship; Liberalism; Comunitarism. 